\title{
$\beta$-D-Glukan, Lektin, Linoleik Asit ve $\beta$-Karoten Bileşiklerinin Karbonik Anhidraz Enzimleri Üzerindeki Etkilerinin Araştırılması
}

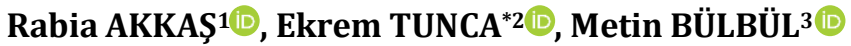 \\ 1,2,3Kütahya Dumlupınar Üniversitesi, Fen Edebiyat Fakültesi, Biyokimya Bölümü, 43100, Kütahya, Türkiye
}

(Alınış / Received: 24.01.2020, Kabul / Accepted: 13.05.2020, Online Yayınlanma / Published Online: 20.08.2020)

Anahtar Kelimeler

$\beta$-D-glukan,

Lektin,

Linoleik asit,

$\beta$-karoten,

Karbonik anhidraz
Özet: $\beta$-D-glukan, lektin, linoleik asit ve $\beta$-karoten; hayvansal, bitkisel ve bakteriyel kaynaklarda bulunan, biyolojik olarak aktif bileşiklerdir. Glokom, dünya genelinde körlüğe neden olma bakımından katarakttan sonra ikinci sırada gelen bir hastalıktır. Karbonik anhidraz (CA) inhibitörleri uzun yıllardır glokom tedavisinde kullanılmaktadır. Ancak, inhibitör ajanların yan etkileri azımsanmayacak derecede çoktur. Yeni CA inhibitörlerinin geliștirilmesi üzerine çeşitli araştırma grupları çalışmalar yapmaktadırlar. Doğal kaynaklı bileşiklerin CA inhibitörü olarak kullanımının araştırılması da son yıllarda popülerlik kazanmıştır. Bu çalışmada, $\beta$ D-glukan, lektin, linoleik asit ve $\beta$-karoten bileşiklerinin, insan eritrosit CA izoenzimleri olan hCA I ve hCA II üzerine etkileri in vitro koşullarda araştırılmıştır. Bileşiklerin $K_{\mathrm{i}}$ değerleri hCA I için $0.45 \pm 0.09 \mu \mathrm{M}-37.02 \pm 17.85 \mu \mathrm{M}$ aralığında, hCA II için $3.12 \pm 1.38 \mu \mathrm{M}-61.23 \pm 25.46 \mu \mathrm{M}$ aralığındadır.

\section{Investigation of the Effects of Compounds, $\beta$-D-Glucan, Lectin, Linoleic Acid and $\beta$ - Carotene on Carbonic Anhydrase Enzymes}

\section{Keywords}

$\beta$-D-glucan,

Lectin,

Linoleic acid,

$\beta$-carotene,

Carbonic anhydrase

\begin{abstract}
D-glucan, lectin, linoleic acid and $\beta$-carotene are biologically active compounds and they are found in animal, herbal and bacterial sources. Glaucoma is the second most common cause of blindness worldwide after cataract. Carbonic anhydrase (CA) inhibitors have been used in the treatment of glaucoma for years. However, inhibitory agents have a lot of side effects. Research groups have been working on the development of new CA inhibitors. Research into the use of compounds of natural origin as CA inhibitors has also gained popularity in recent years. In this study, the inhibitory effects of $\beta$-D-glucan, lectin, linoleic acid and $\beta$ carotene on human erythrocyte carbonic anhydrase isoenzymes, hCA I and hCA II, have been studied in vitro. The $K_{\mathrm{i}}$ values of the compounds were in the range of $0.45 \pm 0.09 \mu \mathrm{M}-37.02 \pm 17.85 \mu \mathrm{M}$ for hCA I, and $3.12 \pm 1.38 \mu \mathrm{M}-61.23 \pm 25.46 \mu \mathrm{M}$ for hCA II.
\end{abstract}

\section{Giriș}

$\beta$-D-glukan, lektin, linoleik asit ve $\beta$-karoten, doğada pek çok canlı türünde karşımıza çıkan biyomoleküllerdir. $\beta$-D-glukan, $\beta(1,3)$ ve $\beta(1,4)$ glikozidik bağlarıyla birbirine bağlanmış glukoz birimlerinden oluşan bir polisakkarittir $[1,2]$. $\beta$-D-glukanın, koroner kalp rahatsızlıkları ve kardiyovasküler rahatsızlı risklerini azalttığl, serum kolesterol seviyesini düşürdüğü ve kan glukoz seviyesini düzenlediği yapılan çalışmalar ile gösterilmiştir [2, 3]. Lektinler, yaşayan bütün canlı türlerinde bulunan ve karbohidrat bağlayıcı olarak tanımlanan proteinlerdir. Spesifik monosakkaritleri ve oligosakkaritleri seçici olarak tanıma ve bu moleküllere geri dönüşümlü olarak bağlanma yetenekleri, lektinlerin başlıca özelliğidir. Bitki yaşamı için temel moleküller olan lektinler, hücrehücre iletişiminde, gelişme ve savunma stratejilerinde önemli roller üstlenirler [4]. Lektin proteinlerinin antibakteriyel, mitojenik, bağışıklığı güçlendirici, anti-proliferatif ve antitümör aktiviteleri vardır $[5,6]$. Terpen yapısında olan $\beta$-karoten ise retinol ve retinoidlerin öncülüdür. $\beta$-karotenin antikanser aktivitesi olmakla birlikte kardiyovasküler rahatsızlıklara karşı da koruma sağlamaktadır [7, 8]. Esansiyel bir yağ asidi olan linoleik asit, iltihaplanma ve adipogenezi indükleme ve endokannabinoid sistem regülasyonunda rol oynayan araşidonik aside dönüştürülür [9]. Linoleik asidin interlökin-6 ve 
interlökin-1 $\beta$ salınımını azaltarak antiinflamatuar etki gösterdiği bildirilmiştir [10].

Karbonik anhidrazlar (CA, E.C. 4.2.1.1), katalitik merkezinde $\mathrm{Zn}^{2+}$ iyonu bulunduran, basit, ancak önemli bir fizyolojik olay olan karbon dioksitin $\left(\mathrm{CO}_{2}\right)$ bikarbonat $\left(\mathrm{HCO}_{3}^{-}\right)$ve protona $\left(\mathrm{H}^{+}\right)$dönüşümlü hidrasyonu reaksiyonunu katalizleyen, yedi farklı gen ailesi $(\alpha, \beta, \gamma, \delta, \zeta, \eta, \theta)$ tarafindan kodlanan metaloenzimlerdir [11-13]. $\alpha$ - gen ailesi tarafindan insanlarda kodlanan on beș farklı CA izoenzimi tespit edilmiştir [11]. CA izoenzimleri; $\mathrm{pH}$ dengesi, elektrolit salınımı, solunum, $\mathrm{CO}_{2}$ ve iyon taşınımı, bazı biyosentez reaksiyonları (glukoneogenez, lipogenez vb.) ve tümör oluşumu gibi birçok önemli fizyolojik süreçte aktif rol oynarlar[14-16]. Göz dokusunda bulunan sitozolik CA izoenzimi olan hCA II, göz içi sıvısının (aköz humor) oluşumunda görev alır [17]. Glokom, göz içi basıncındaki (IOP) yükselmeye bağlı olarak kademeli görme alanı kaybı ile karakterize bir hastalıktır [18, 19]. CA inhibitörleri aköz humor oluşumunu yavaşlatarak, göz içi basıncını düşürürler. Glokomun tedavisi için, göz içi sıvısının oluşumunda rol alan CA izoenzimleri terapötik hedef konumundadırlar $[20,21]$.

Son yıllarda, hastalıkların tedavisi veya önlenmesi amacıyla sentetik bileşiklerin yerine, olası yan etkilerinin daha az olması nedeniyle, doğal bileşiklerin kullanımında artış meydana gelmiştir. $\mathrm{Bu}$ bağlamda, kuersetin, gallik asit, kafeik asit, ellajik asit, resveratol ve kateşin gibi polifenoller ile spermin ve spermidin gibi bazı doğal bileşiklerin CA inhibisyon çalışmaları çeşitli gruplar tarafından yapılmıştır [15, 16, 22-24]. Ancak $\beta$-D-glukan, lektin, linoleik asit ve $\beta$-karoten bileşiklerinin CA izoenzimleri üzerindeki etkilerinin incelendiği bir çalışma literatürde mevcut değildir.

Bu çalışmada, insan karbonik anhidraz izoenzimleri olan hCA I ve hCA II insan eritrositlerinden afinite kromatografisi ile saflaştırılmış ve $\beta$-D-glukan, lektin, linoleik asit ve $\beta$-karoten bileşiklerinin bu izoenzimlerin üzerindeki etkileri in vitro olarak incelenmiştir.

\section{Materyal ve Metot}

\subsection{Materyal}

Araştırma kapsamında kullanılan $\beta$-D-glukan (arpa), lektin (fıstık), linoleik asit ve $\beta$-karoten bileşikleri ve diğer tüm kimyasallar Sigma-Aldrich firmasından temin edilmiştir. Eritrosit hücre membranlarının hemolizattan uzaklaştırılması soğutmalı santirfüj (SIGMA 3K30) kullanılarak sağlanmıștır. Afinite kromatografisi esnasinda peristaltik pompa (ISMATEC REGLO Digital MS-2/6) kullanılmıștır. İzoenzimlerin esteraz aktiviteleri ve bileşiklerin esteraz inhibisyon potansiyelleri UV-Visible spektrofotometre (SHIMADZU UV1700 PharmaSpec) kullanılarak belirlenmiștir.

\section{2. hCA I ve hCA II izoenzimlerinin saflaştırılması}

Antikoagülantlı tüplere alınan kan örnekleri 1500 rpm devirde $20 \mathrm{dk}$ santrifüjlendi ve plazma ayrıldı. Eritrositler izotonik çözelti (\%0.9 NaCl) ile birkaç kez yıkandı ve hacimlerinin 1.5 katı buzlu su ile hemoliz edildi. Hücre membranları, hemolizatın $4 \quad{ }^{\circ} \mathrm{C}$ sıcaklıkta, $20000 \mathrm{rpm}$ devirde $30 \mathrm{dk}$. süreyle santrifüj edilmesi suretiyle ortamdan uzaklaștırıldı. Hemolizatın pH'ı katı TRIS (tris(hidroksimetil)amino metan) kullanılarak 8.7 değerine ayarlandı ve daha önceden $25.0 \mathrm{mM}$ TRIS-HCl/100 mM Na $2 \mathrm{SO}_{4}$ (pH 8.7) çözeltisi ile dengelenmiş afinite kolonuna (Sepharose ${ }^{\circledR 4 B}$ B-L-tirozin- $p$-aminobenzensülfonamit) yüklendi. $25.0 \mathrm{mM}$ TRIS- $\mathrm{HCl} / 22.0 \mathrm{mM} \mathrm{Na} \mathrm{SO}_{4}(\mathrm{pH}$ 8.7) çözeltisi ile yapılan yıkama işlemi sonrasında, hCA I izoenzimi $1000 \mathrm{mM} \mathrm{NaCl} / 25.0 \mathrm{mM} \mathrm{Na} 2 \mathrm{HPO}_{4}$ (pH 6.3) çözeltisi kullanılarak, hCA II izoenzimi ise $100 \mathrm{mM} \mathrm{NaCH} 3 \mathrm{COO} / 500 \mathrm{mM} \mathrm{NaClO}$ (pH 5.6) çözeltisi ile afinite kolonundan elüe edildi [25]. Protein miktarı Bradford metoduna göre belirlendi [26]. İzoenzimlerin saflık kontrolleri SDS-PAGE ile yapildı [27].

\subsection{Saflaştırılan enzimlerin hidrataz ve esteraz aktivitelerinin belirlenmesi}

hCA I ve hCA II' nin $\mathrm{CO}_{2}$ hidrataz aktivitesi pH-stat yöntemi ile belirlendi. $\mathrm{Bu}$ yöntemin prensibi, $\mathrm{CO}_{2}$ bileşiğinin $\mathrm{H}_{2} \mathrm{O}$ ile reaksiyonu sonucu açığa çlkan $\mathrm{H}^{+}$ iyonundan kaynaklı olarak, $\mathrm{pH}^{\prime}$ in 8.15 den 6.15 e düşmesi için geçen sürenin $\mathrm{pH}$ metre ve kronometre kullanılarak belirlenmesine dayanır. [28, 29].

Enzim aktivitesi, $\left(\left(t_{0}-t_{c}\right) / t_{c}\right)$ eşitliği kullanılarak hesaplandı. Burada to enzimsiz $\mathrm{CO}_{2}$ hidrasyon süresi, $t_{c}$ enzimli $\mathrm{CO}_{2}$ hidrasyon süresidir.

Esteraz aktivitesi, substrat olarak kullanılan 4nitrofenilasetat bileșiğinin, CA izoenzimleri katalizörlüğünde, 4-nitrofenol(at) bileşiğine hidrolizi esnasında meydana gelen absorbans değișiminin 348 $\mathrm{nm}$ de ölçülmesi ile belirlenmiştir. Ölçümler $25{ }^{\circ} \mathrm{C}$ sıcaklıkta, 3 dakika süreyle yapılmıștır [30].

\section{4. Çalıșmada kullanılan bileșiklerin IC $_{50}$ değerlerinin ve $K_{\mathrm{i}}$ sabitlerinin belirlenmesi}

Bileşiklerin $\mathrm{IC}_{50}$ değerlerinin belirlenmesi için, farklı inhibitör konsantrasyonlarında, hCA I ve hCA II izoenzimlerinin hidrataz ve esteraz aktiviteleri, "Kesim 2.3" de tarif edildiği şekilde ölçüldü. İnhibitörsüz ortamdaki ölçümlerde enzim aktivitesi \%100 kabul edilerek, \%Aktivite-[İnhibitör] eğrileri çizildi ve eğrinin denklemi yardımıyla bileşiklerin $\mathrm{IC}_{50}$ değerleri belirlendi [17]. 
İnhibisyon sabiti $\left(K_{\mathrm{i}}\right)$, izoenzimlerin esteraz aktivitesi esas alınarak belirlendi. $K_{\mathrm{i}}$ değerlerinin belirlenmesi için, enzimli reaksiyon hızını $\% 30, \% 50$ ve $\% 70$ oranında yavaşlatan üç farklı inhibitör konsantrasyonu seçildi ve her bir inhibitör konsantrasyonu için beş farklı substrat konsantrasyonunda $(0.3,0.4,0.5,0.6$ ve $0.7 \mathrm{mM}) \mathrm{CA}$ enzim aktiviteleri ölçüldü. Aynı ölçümler inhibitörsüz ortamda da tekrarlandı ve Lineweaver-Burk eğrileri çizilerek $K_{\mathrm{i}}$ sabiti belirlendi [31].

\section{Bulgular}

\section{1. hCA I ve hCA II izoenzimlerinin saflaştırılması}

hCA I ve hCA II, Sepharose ${ }^{\circledR 4 B-L-t i r o z i n-~} p$-aminobenzensülfonamit afinite kolonundan saflaştırıldı. Elüatlarda kalitatif protein analizi, kantitatif protein miktar analizi ve hidrataz aktivitesi ölçümü gerçekleştirildi (Şekil 1, Şekil 2)

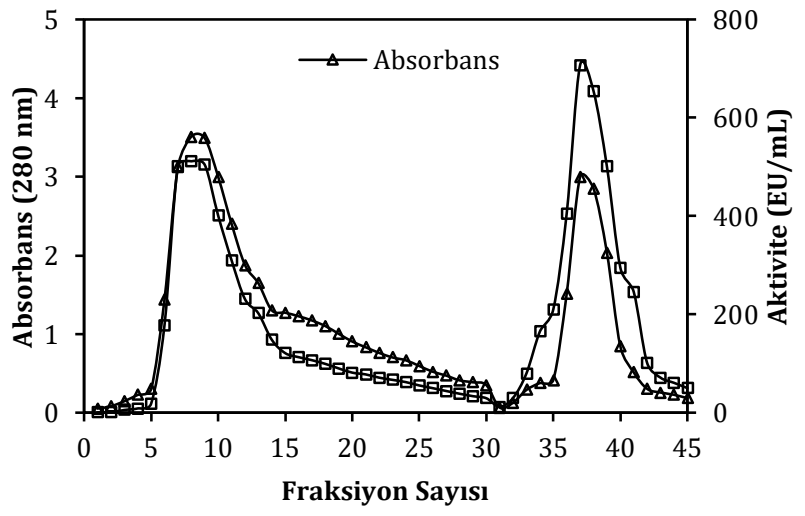

Şekil 1. hCA I ve hCA II elüatlarında yapılan kalitatif protein analizi ve hidrataz aktivitesi ölçümü (1. - 30. fraksiyon hCA I, 31. - 45. fraksiyon hCA II içindir).

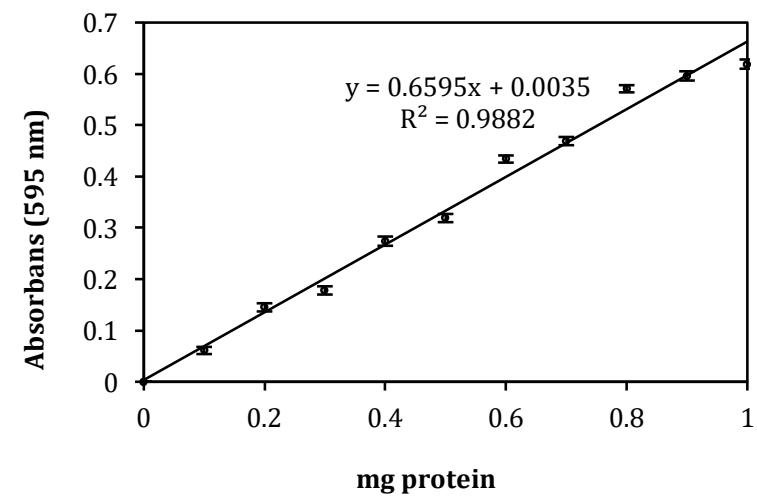

Şekil 2. Bradford metoduna göre olușturulan standart eğri.
Afinite kolonundan elüe edilen hCA I izoenzimi 1345.82 EU.mg protein ${ }^{-1}$ spesifik aktivite ile 184.88 kat, hCA II izoenzimi ise 3928.61 EU.mg protein-1 spesifik aktivite ile 539.68 kat saflaștırılmıștır (Tablo 1). Ayrıca izoenzimlerin saflıkları SDS-PAGE ile kontrol edilmiştir (Şekil 3).

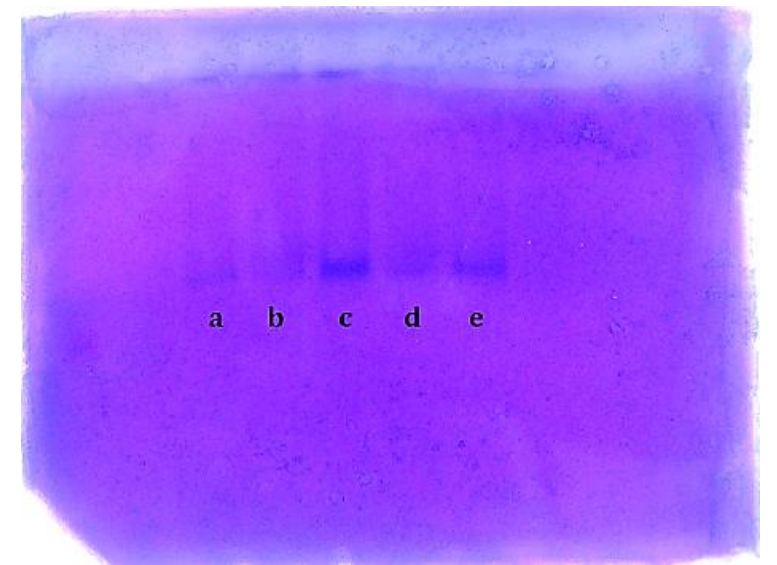

Şekil 3. Saflaştırılan enzimlerin SDS-PAGE analizi (a: standart sığır karbonik anhidraz (29 kDa), b, c: saflaștırılan hCA I, d, e: saflaştırılan hCA II).

\section{2. $\beta$-D-glukan, lektin, linoleik asit ve $\beta$-karoten bileşiklerinin $\mathrm{IC}_{50}$ değerleri ve $K_{i}$ sabitlerinin belirlenmesi}

Bileşiklerin hidrataz ve esteraz IC $_{50}$ değerlerinin belirlenmesi için, saflaștırılan CA izoenzimlerinin hidrataz ve esteraz aktiviteleri, farklı konsantrasyonlardaki $\beta$-D-glukan, lektin, linoleik asit ve $\beta$-karoten varlığında "Kesim 2.3" de tarif edildiği şekilde ölçül-dü. Her ölçüm üç kez tekrarlandı ve \%Aktivite-[İnhibitör] eğrileri çizilerek bileşiklerin IC50 değerleri hesaplandı (Tablo 2).

Tablo 2 de görüldüğü üzere, $\beta$-D-glukan bileșiği hCA I ve hCA II izoenzimlerinin hidrataz ve esteraz aktiviteleri üzerinde inhibisyon etkisi göstermemiştir. $\beta$-karoten bileşiği ise, izoenzimlerin hidrataz aktivitelerini inhibe etmemiş, esteraz aktivitelerini ise ortalama bir düzeyde inhibe etmiştir. Lektin bileșiği, CA izoenzimlerinin hidrataz ve esteraz aktiviteleri üzerinde inhibisyon etkisi göstermiştir. Linoleik asit bileşiği ise özellikle CA izoenzimlerinin esteraz aktiviteleri üzerinde en güçlü inhibitör etkiye sahip bileșiktir. Hidrataz ve esteraz IC $_{50}$ değerlerinin hesaplanması için çizilen eğrilere birer örnek "Şekil 4" ve "Şekil 5" de gösterilmiştir.

Tablo 1. Saflaștırılan enzimlerin spesifik aktivite değerleri ve saflaștırma verimleri.

\begin{tabular}{lcccccccc}
\hline $\begin{array}{c}\text { Saflaştırma } \\
\text { Adımı }\end{array}$ & $\begin{array}{c}\text { Aktivite } \\
\text { (EU/mL) }\end{array}$ & $\begin{array}{c}\text { Toplam } \\
\text { Hacim } \\
\text { (mL) }\end{array}$ & $\begin{array}{c}\text { Protein } \\
\text { (mg/mL) }\end{array}$ & $\begin{array}{c}\text { Toplam } \\
\text { Protein } \\
\text { (mg) }\end{array}$ & $\begin{array}{c}\text { Toplam } \\
\text { Aktivite } \\
\text { (EU) }\end{array}$ & $\begin{array}{c}\text { Spesifik } \\
\text { Aktivite } \\
\text { (EU/mg } \\
\text { protein) }\end{array}$ & $\begin{array}{c}\text { Verim } \\
\text { (\%) }\end{array}$ & $\begin{array}{c}\text { Saflaştırma } \\
\text { Katsayısı }\end{array}$ \\
\hline Hemolizat & 105.19 & 50.00 & 14.45 & 722.50 & 5259.50 & 7.28 & 100.00 & 1.00 \\
Afinite (hCAI) & 511.41 & 5.00 & 0.38 & 1.90 & 2557.05 & 1345.82 & 48.62 & 184.88 \\
Afinite (hCAII) & 707.15 & 5.00 & 0.18 & 0.90 & 3535.75 & 3928.61 & 67.23 & 539.68 \\
\hline
\end{tabular}


Tablo 2. Bileşiklerin hesaplanan $\mathrm{IC}_{50}$ değerleri ve $K_{\mathrm{i}}$ sabitleri.

\begin{tabular}{|c|c|c|c|c|c|c|c|c|}
\hline \multirow[b]{2}{*}{ Bileşik } & \multicolumn{2}{|c|}{ Hidrataz $\mathrm{IC}_{50}(\mu \mathrm{M}) \pm \mathrm{SD}^{\mathrm{a}, \mathrm{b}}$} & \multicolumn{2}{|c|}{ 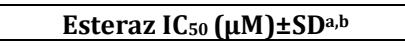 } & \multicolumn{4}{|c|}{$K_{\mathrm{i}}(\mu \mathrm{M}) \pm \mathrm{SD}^{\mathrm{a}, \mathrm{b}}$} \\
\hline & hCA I & hCA II & hCA I & hCA II & hCA I & 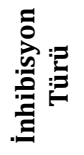 & hCA II & 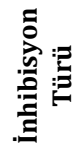 \\
\hline$\overline{A A Z c}$ & $0.39 \pm 0.008$ & $0.20 \pm 0.005$ & $0.42 \pm 0.004$ & $0.31 \pm 0.008$ & $0.26 \pm 0.003$ & \multirow{4}{*}{ 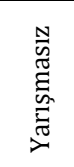 } & $0.14 \pm 0.005$ & \multirow{4}{*}{ 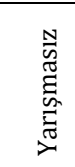 } \\
\hline Lektin & $13.43 \pm 1.93$ & $20.22 \pm 4.33$ & $20.07 \pm 3.71$ & $8.31 \pm 0.59$ & $8.35 \pm 2.89$ & & $4.76 \pm 1.38$ & \\
\hline Linoleik asit & $60.25 \pm 18.26$ & $104.50 \pm 9.53$ & $0.71 \pm 0.04$ & $7.09 \pm 0.44$ & $0.45 \pm 0.09$ & & $3.12 \pm 1.38$ & \\
\hline$\beta$-karoten & - & - & $161.70 \pm 20.01$ & $100.38 \pm 14.48$ & $37.02 \pm 17.85$ & & $61.23 \pm 25.46$ & \\
\hline$\beta$-D-glukan & - & - & - & - & - & - & - & - \\
\hline
\end{tabular}

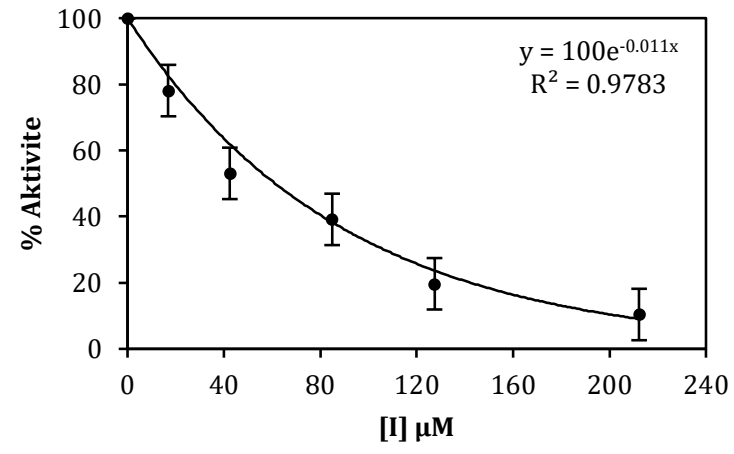

Şekil 4. Linoleik asit bileşiğinin hCA I hidrataz $\mathrm{IC}_{50}$ değerinin belirlenmesi için çizilen grafik.

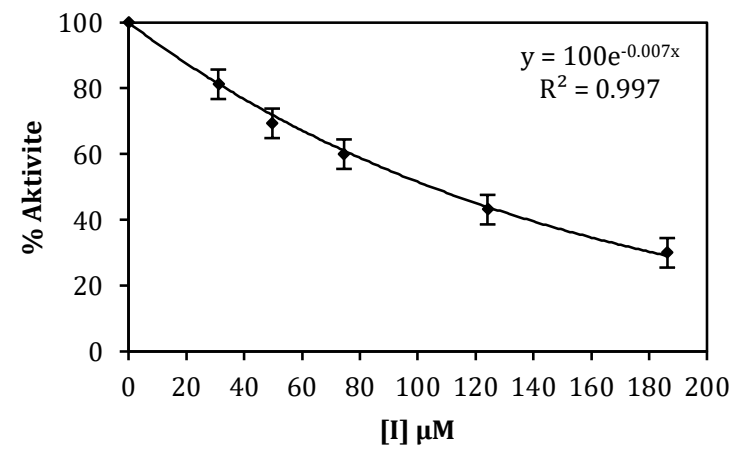

Şekil 5. $\beta$-karoten bileşiğinin hCA II esteraz $\mathrm{IC}_{50}$ değerinin belirlenmesi için çizilen grafik.

Bileşiklerin $K_{\mathrm{i}}$ değerleri ise, esteraz aktivitesi ölçümü esas alınarak "Kesim 2.4" de tarif edildiği şekilde hesaplandı. Üç farklı inhibitör konsantrasyonunun her biri için beş farklı substrat konsantrasyonunda yapılan esteraz aktivitesi ölçümleri üçer kez tekrarlandı ve elde edilen ortalama değerler kullanılarak çizilen Lineweaver-Burk grafikleri yardımıyla $K_{\mathrm{i}}$ sabitleri hesaplandı (Tablo 2). Ayrıca çizilen grafikler yardımıyla inhibisyonun türü de belirlendi.

Tablo 2 deki değerler incelendiğinde, özellikle linoleik asit bileșiğinin hCA I $K_{\mathrm{i}}$ sabitinin, referans bileşik olan AAZ bileşiğinin $K_{\mathrm{i}}$ sabitine yakın bir değerde olması kayda değer bir durumdur. hCA I ve
hCA II izoenzimlerinin esteraz aktiviteleri üzerinde inhibisyon gösteren tüm bileşiklerin, inhibisyon mekanizmalarının yarıșmasız mekanizma üzerinden yürüdüğü belirlenmiştir. Çalışma kapsamında çizilen Lineweaver-Burk grafiklerine bir örnek "Şekil 6" da gösterilmiştir.

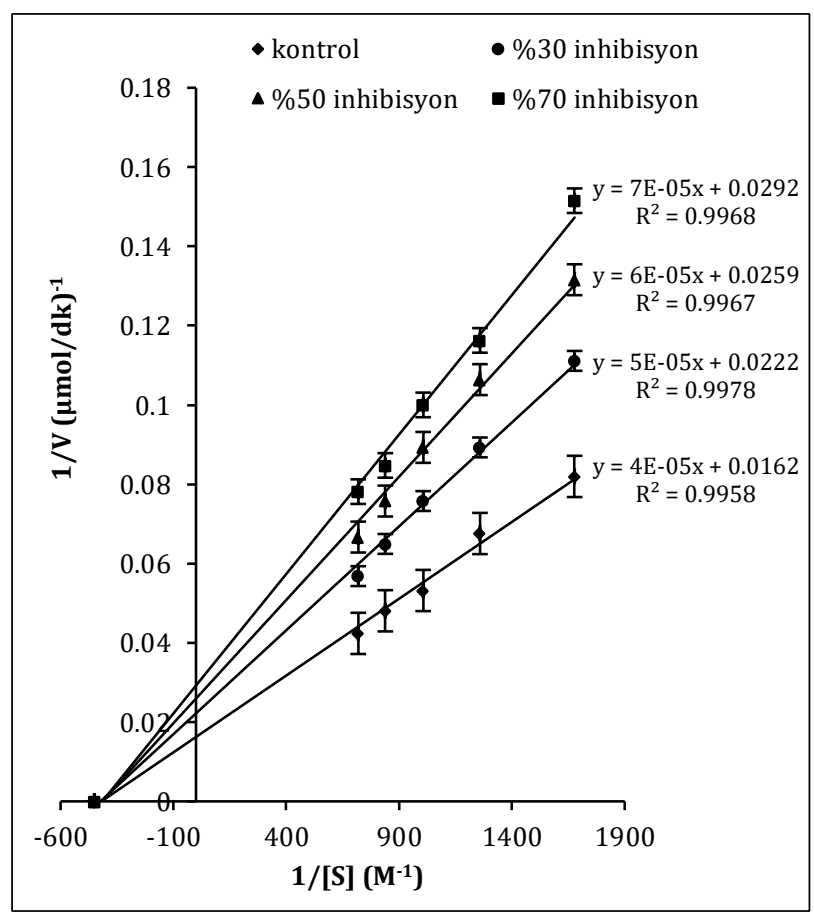

Şekil 6. Linoleik asit bileşiğinin hCA I $K_{\mathrm{i}}$ sabitinin ve inhibisyon türünün belirlenmesi için çizilen grafik

\section{Tartışma ve Sonuç}

Karbonik anhidrazlar (CA); taşıma ve homeostaz, glukoneogenez, lipogenez ve ürogenez gibi biyosentez reaksiyonları, solunum, kalsifikasyon, tümör oluşumu, çeşitli organ ve dokulardan elektrolit salınımı ve kemik resorpsiyonu gibi kritik patofizyolojik süreçlerle ilișkili olan $\mathrm{CO}_{2} / \mathrm{HCO}_{3}^{-}$ dönüşümünü katalizleyen metaloenzimlerdir [32]. Bu çalışmada insan eritrositlerinden hCA I ve hCA II, Sepharose ${ }^{\circledR} 4 \mathrm{~B}$-L-tirozin- $p$-aminobenzensülfonamit afinite kromatografisi ile saflaştırıldı. hCA I izoenziminin 1345.82 EU.mg protein ${ }^{-1}$ spesifik 
aktivite ile 184.88 kat, hCA II izoenziminin ise 3928.61 EU.mg protein ${ }^{-1}$ spesifik aktivite ile 539.68 kat saflaştırıldığı belirlendi (Tablo 1). Standart sığır karbonik anhidrazı (29 kDa) kullanılarak yapılan SDS-PAGE analizi, hCA I ve hCA II izoenzimlerinin afinite kolonundan saf bir şekilde elüe edildiğini göstermektedir (Şekil 3).

CA izoenzimlerinin aktif bölgesi, genişliği $12 \AA$, derinliği 13 Å olan konik bir boşluk şeklindedir. Aktif bölge boșluğu, bir tarafı hidrofobik amino asitlerden, diğer tarafı ise hidrofilik amino asitlerden oluşan iki kısma bölünmüş durumdadır (Şekil 7) [11]. Bu durum enzimin geniş bir bileşik sınıfı tarafından inhibe edilmesini sağlamaktadır.

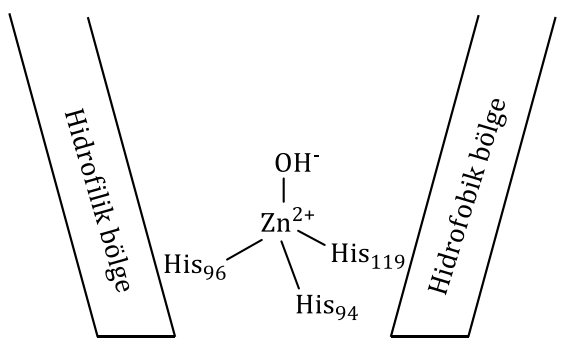

Şekil 7. CA izoenzimlerinin aktif bölgesinin şematik gösterimi.

CA inhibitörleri doğrudan çinkoya bağlanarak, çinko iyonuna bağlı hidroksit iyonuna bağlanarak, aktif bölge girişindeki amino asitlerle etkileşip aktif bölge girișini kapatarak ya da aktif bölgenin dışına dışına bağlanıp konformasyonu değiştirerek etki gösterirler [33].

Çalışmada kullanılan bileşikler olan $\beta$-D-glukan, lektin, linoleik asit ve $\beta$-karoten bileşiklerinin hCA I ve hCA II' nin hidrataz aktiviteleri üzerindeki etkileri incelendiğinde, $\beta$-D-glukan ve $\beta$-karoten bileşiklerinin inhibisyon etkisi göstermediği, lektin ve linoleik asit bileşiklerinin ise hidrataz aktivitesini inhibe ettikleri görülmektedir. $\beta$-D-glukan molekülünün yapısı incelendiğinde bir polisakkarit olduğu görülmektedir (Şekil 8). Yapısındaki $-\mathrm{OH}$ gruplarından dolayı, $\beta$-D-glukan molekülünün, fenolik bileşiklerin CA inhibisyon mekanizması olan çinko iyonuna bağlı hidroksit iyonuna bağlanarak hCA I ve hCA II izoenzimlerinin hidrataz aktivitelerini inhibe etmesi beklenirdi. İnhibisyon gözlenmemesi $\beta$-Dglukan molekülünün sterik etkisi ile açıklanabilir.

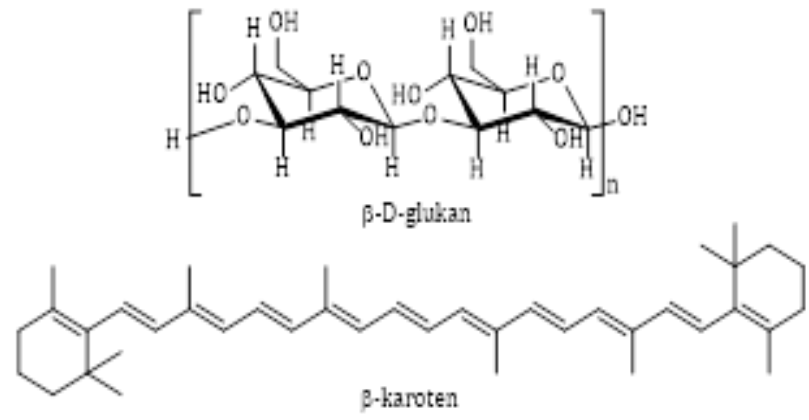

Şekil 8. $\beta$-D-glukan ve $\beta$-karoten moleküllerinin yapıları. $\beta$-karoten molekülünün, aktif bölgedeki hidrofobik amino asitlerle etkileştiği, ancak bu etkileşimin hCA I ve hCA II izoenzimlerinin hidrataz aktivitelerini inhibe edebilecek düzeyde olmadığ edilmektedir. hCA I ve hCA II izoenzimlerinin esteraz aktivitelerini inhibe etmesinden dolayı $\beta$-karoten bileşiğinin enzim ile etkileşmediğini söyleyemeyiz.

Çalışmada kullanılan lektin molekülü (fıstık), doğal hali $100.8 \mathrm{kDa}$ molekül ağırlığında olan tetramerik yapıdaki bir proteindir. Çalışmamızda kullanılan şekli ise $25.2 \mathrm{kDa}$ ağrılığındaki monomeridir (Şekil 9). hCA I ve hCA II izoenzimlerinin hidrataz aktivitelerini inhibe eden lektin molekülünün, bu izoenzimlerinin aktif bölge girişini kapatarak inhibisyon etkisi gösterdiği düşünülmektedir. Kontrol bileşiği olan AAZ bileşiğine göre zayıf inhibisyon göstermekle beraber, lektin molekülü kayda değer bir inhibisyon etkisine sahiptir.

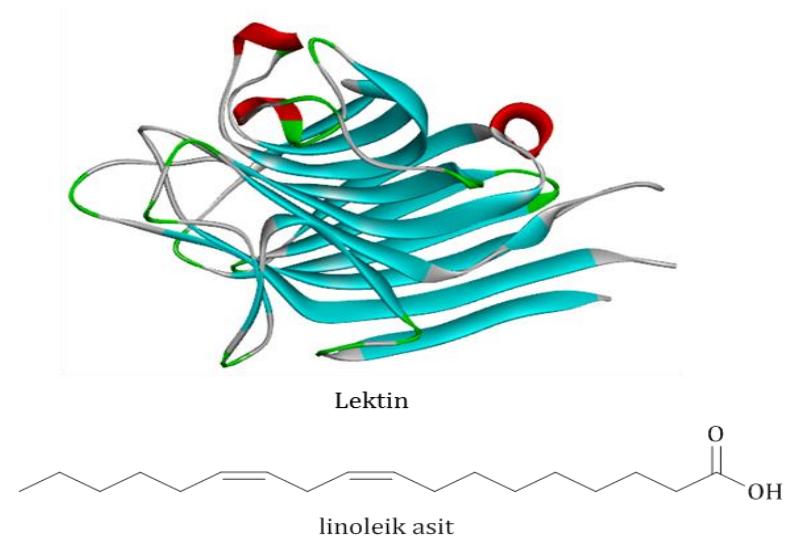

Şekil 9. Lektin (PDB: 2PEL) ve linoleik asit molekül-lerinin yapıları.

Linoleik asit bileşiği de lektin molekülüne göre zayıf olmakla beraber, hCA I ve hCA II izoenzimlerinin hidrataz aktivitelerini inhibe etmiștir. Linoleik asidin hCA I ve hCA II ile etkileşme şeklinin, $-\mathrm{COOH}$ grubunun çinko iyonuna bağlı hidroksit grubu ile etkileșip, hidrofobik kuyruğunun ise aktif bölgedeki hidrofobik amino asitlerle etkileşerek veya $-\mathrm{COOH}$ grubunun aktif bölgenin hidrofilik kısmındaki amino asitlerle etkileşip, hidrofobik kuyruğunun ise aktif bölgedeki hidrofobik amino asitlerle etkileşmek suretiyle olduğu tahmin edilmektedir.

Bileşiklerin hCA I ve hCA II esteraz aktiviteleri üzerindeki etkileri incelendiğinde, $\beta$-D-glukan molekülünün inhibisyon etkisi göstermediği görülmektedir. $\mathrm{Bu}$ durumun hidrataz aktivitesi inhibisyonuna benzer şekilde, sterik etkilerden kaynaklandığı tahmin edilmektedir. Linoleik asit bileşiği ise, hCA I ve hCA II esteraz aktivitesi üzerinde önemli derecede inhibitör etki göstermiştir. Tablo 2 incelendiğinde, linoleik asidin hCA I üzerindeki inhibisyon etkisinin, AAZ bileşiğinin inhibisyon etkisine yakın bir düzeyde olduğu görülmektedir. Lektin molekülünün, hCA I ve hCA II izoenzimlerinin esteraz aktiviteleri üzerindeki inhibisyon şiddetinin, 
aynı izoenzimlerin hidrataz aktiviteleri üzerinde gösterdiği inhibisyon şiddetine yakın olduğu görülmektedir. $\beta$-karoten bileşiği ise, hCA I ve hCA II izoenzimlerinin hidrataz aktivitelerini inhibe etmediği halde, esteraz aktivitelerini inhibe etmiștir. $\beta$-karoten molekülünün hidrofobik yapısından dolayı, hCA I ve hCA II izoenzimlerinin aktif bölgelerindeki hidrofobik amino asitlerle etkileşime girdiği ve bu etkileşimin, izoenzimlerin esteraz aktivitelerini yavaşlatıcı yönde etki gösterdiği düşünülmektedir.

Bileşiklerin $K_{\mathrm{i}}$ inhibisyon sabitlerinin belirlenmesi için yapılan inhibisyon çalışmaları sonucunda, hCA I ve hCA II esteraz aktiviteleri üzerinde inhibisyon etkisi gösteren tüm bileșiklerin yarışmasız inhibisyon mekanizması üzerinden etki gösterdiği belirlenmiştir. Diğer araştırma grupları tarafından, bazı doğal bileşiklerin CA izoenzimlerine etkilerinin incelendiği çalışmalar mevcuttur. p-kumarik asit, kafeik asit, gallik asit, kuersetin, ellajik asit, kurkumin ve silmarin gibi fenolik bileșiklerin inhibisyon etkilerinin incelendiği çalıșmalarda bu moleküllerin $K_{\mathrm{i}}$ değerlerinin ortalama $2.0 \mu \mathrm{M}$ civarında seyrettiği görülmektedir [23, 34, 35]. Kumarin bileşiğinin CA izoenzimleri üzerine inhibisyon etkisinin araştırıldığı başka bir çalışmada, bu bileşiğin hCA I için $K_{\mathrm{i}}$ değerinin $3.1 \mu \mathrm{M}$, hCA II için $K_{\mathrm{i}}$ değerinin $9.2 \mu \mathrm{M}$ olduğu belirlenmiştir [36]. Carta vd. [37] tarafından, doğal kaynaklı poliamin bileşikleri olan spermin ve spermidin bileşiklerinin CA izoenzimleri üzerindeki inhibisyon etkilerinin incelendiği bir çalışmada spermin bileşiğinin zayıf inhibisyon etkisi gösterdiği, spermidin bileşiğinin ise hCA I için $K_{\mathrm{i}}$ değerinin 1.40 $\mu \mathrm{M}, \quad$ hCA II için $K_{\mathrm{i}}$ değerinin $1.11 \mu \mathrm{M}$ olduğu bulunmuştur. Bir flavonoid türevi olan taksifolin (dihidrokuersetin) bileşiğinin ise kuersetin bileşiğinden çok daha güçlü CA inhibitörü olduğu bulunmuştur [38].

Mevcut çalışma kapsamında, hCA I ve hCA II izoenzimleri üzerinde etkisi incelenen moleküllerin inhibisyon potansiyellerinin, daha önce çalışılmış olan ve bir kısmı yukarıda özetlenen bileșiklerin büyük çoğunluğunun inhibisyon potansiyelleri ile kıyaslanabilir büyüklükte olduğu görülmektedir. Öte yandan bu çalışmada gözlemlenen inhibisyon potansiyelleri pek çok sentetik bileşiğin inhibisyon potansiyeli ile yakın seviyededir. Dolayısıyla bu çalışma kapsamındaki bileşiklerin, glokom tedavisi araştırmalarında daha ileri çalışmalar olan in vivo çalışmalarda kullanılabilecek potansiyelde oldukları açıkça ortadadır.

\section{Teşekkür}

Desteklerinden dolayı Kütahya Dumlupınar Üniversitesi Bilimsel Araştırma Projeleri Komisyonuna teşekkürlerimizi sunarız (Proje No: 2010/8).

\section{Kaynakça}

[1] Ai, Q., Mai, K., Zhang, L., Tan, B., Zhang, W., Xu, W., Li, H. 2007. Effects of dietary $\beta-1,3$ glucan on innate immune response of large yellow croaker, Pseudosciaena crocea. Fish \& Shellfish Immunology, 22, 394-402.

[2] Tiwari, U., Cummins, E. 2011. Meta-analysis of the effect of $\beta$-glucan intake on blood cholesterol and glucose levels. Nutrition, 27, 1008-1016.

[3] Dietrich-Muszalska, A., Olas, B., Kontek, B., RabeJabłońska, J. 2011. Beta-glucan from Saccharomyces cerevisiae reduces plasma lipid peroxidation induced by haloperidol. International Journal of Biological Macromolecules, 49, 113-116.

[4] Bellande, K., Bono, J. J., Savelli, B., Jamet, E., Canut, H. 2017. Plant lectins and lectin receptorlike kinases: How do they sense outside?. International Journal of Molecular Sciences, 18, 1164.

[5] Zheng, S., Li, C., Ng, B. T., Wang, H. X. 2007. A lectin with mitogenic activity from edible wild mushroom Boletus edulis. Process Biochemistry, $42,1620-1624$.

[6] Li, Y. R., Liu, Q. H., Wang, H. X., Ng, T. B. 2008. A novel lectin with potent antitumor, mitogenic and HIV-1 reverse transcriptase inhibitory activities from the mushroom Pleutorus citrinopleatus. Biochimica et Biophysica Acta, 1780, 51-57.

[7] Dulińska, J., Gil, D., Zagajewski, J., Hartwich, J., Bodzioch, M., Dembińska-Kieć, A., Langmann, T., Schmitz, G., Laidler, P. 2005. Different effect of beta-carotene on proliferation of prostate cancer cells. Biochimica et Biophysica Acta, 1740, 189201.

[8] Qiu, D., Chen, Z. R., Li, H. R. 2009. Effect of heating on solid $\beta$-carotene. Food Chemistry, 112, 344-349.

[9] Naughton, S. S., Mathai, M. L., Hryciw, D. H., McAinch, A. J. 2016. Linoleic acid and pathogenesis of obesity. Prostaglandins \& Other Lipid Mediators, 125, 90-99.

[10] Jung, S., Han, B. H., Nam, K., Ahn, D. U., Lee, J. H., Jo, C. 2011. Effect of dietary supplementation of gallic acid and linoleic acid mixture or their synthetic salt on egg quality. Food Chemistry, 129(3), 822-829.

[11] Alterio, V., Di Fiore, A., D’Ambrosio, K., Supuran, C. T., De Simone, G. 2012. Multiple binding modes of inhibitors to carbonic anhydrase: How to design specific drugs targeting 15 different isoforms?. Chemical Reviews, 112, 4421-4468. 
[12] Supuran, C. T. 2008. Carbonic anhydrases: novel therapeutic applications for inhibitors and activators. Nature Reviews Drug Discovery, 7, 168-181.

[13] Kikutani, S., Nakajima, K., Nagasato, C., Tsuji, Y., Miyatake, A., Matsuda, Y. 2016. Thylakoid luminal $\theta$-carbonic anhydrase critical for growth and photosynthesis in the marine diatom Phaeodactylum tricornutum. Proceedings of the National Academy of Sciences, 113, 9828-9833.

[14] Winum, J. Y., Vullo, D., Casini, A., Montero, J. L., Scozzafava, A., Supuran, C. T. 2003. Carbonic anhydrase inhibitors. Inhibition of cytosolic isozymes I and II and transmembrane tumor associated isozyme IX with sulfamates including EMATE also acting as steroid sulfatase inhibitors. Journal of Medicinal Chemistry, 46, 2197-2204.

[15] Șentürk, M., Gülçin, İ., Beydemir, Ş., Küfrevioğlu, Ö. İ., Supuran C. T. 2011. In vitro inhibition of human carbonic anhydrase I and II isozymes with natural phenolic compounds. Chemical Biology and Drug Design, 77, 494-499.

[16] Sarıkaya, S. B. Ö, Topal, F., Şentürk, M., Gülçin, İ., Supuran, C. T. 2011. In vitro inhibition of $\alpha-$ carbonic anhydrase isozymes by some phenolic compounds. Bioorganic \& Medicinal Chemistry, 21, 4259-4262.

[17] Yenikaya, C., İlkimen, H., Demirel, M. M., Ceyhan, B., Bülbül, M., Tunca, E. 2016. Preparation of two maleic acid sulfonamide salts and their copper(II) complexes and antiglaucoma activity studies. Journal of Brazilian Chemical Society, 27(10), 1706-1714.

[18] Scozzafava, A., Banciu, M. D., Popescu, A., Supuran, C. T. 2000. Carbonic anhydrase inhibitors: Inhibition of isoenzymes I, II and IV by sulfonamide and sulfamic acid derivatives. Journal of Enzyme Inhibition and Medicinal Chemistry, 15, 443-453.

[19] Schuman, J. S. 2000. Antiglaucoma medications: a review of safety and tolerability issues related to their use. Clinical Therapeutics, 22, 167-208.

[20] Brzozowski, Z., Słaviński, J., Innocenti, A., Supuran, C. T. 2010. Carbonic anhydrase inhibitors. Regioselective synthesis of novel 1substituted 1,4-dihydro-4-oxo-3-pyridinesulfonamides and their inhibition of human cytosolic isozymes I and II and transmembrane cancerassociated isozymes IX and XII. European Journal of Medicinal Chemistry, 45, 3656-3661.

[21] Balaydın, H. T., Şentürk M., Göksu, S., Menzek A. 2012. Synthesis and carbonic anhydrase inhibitory properties of novel bromophenols and their derivatives incuding natural products: Vidalol B. European Journal of Medicinal Chemistry, 54, 423-428.
[22] Supuran, C. T. 2011. Carbonic anhydrase inhibition with natural products: novel chemotypes and inhibition mechanisms. Molecular Diversity, 15, 305-316.

[23] Innocenti, A., Sarıkaya, S. B. Ö., Gülçin, İ, Supuran, C. T. 2010. Carbonic anhydrase inhibitors. Inhibition of mammalian isoforms I-XIV with a series of natural product polyphenols and phenolic acids. Bioorganic \& Medicinal Chemistry, 18, 2159-2164.

[24] Sarıkaya, S. B. Ö., Gülçin, İ., Supuran, C. T., 2010. Carbonic anhydrase inhibitors: Inhibition of human erythrocyte isozymes I and II with a series of phenolic acids. Chemical Biology and Drug Design, 75, 515-520.

[25] Rickli, E. E., Ghazanfar, S. A., Gibbons, B. H., Edsall, J. T. 1964. Carbonic anhydrases from human erythrocytes. Preparation and properties of two enzymes. Journal of Biological Chemistry, 239, 1065-1078.

[26] Bradford, M. M. 1976. A rapid and sensitive method for quantitation of microgram quantities of protein utilizing the principle of protein-dye binding. Analytical Biochemistry, 72, 248-254.

[27] Laemmli, U. K. 1970. Cleavage of structural proteins during the assembly of the head of bacteriophage T4. Nature, 227, 680-685.

[28] Wilbur, K. M., Anderson, N. G. 1948. Electrometric and colorimetric determination of carbonic anhydrase. Journal of Biological Chemistry, 176, 147-154.

[29] Maren, T. H. 1960. A simplified micromethod for the determination of carbonic anhydrase and its inhibitors. Journal of Pharmacology and Experimental Therapeutics, 130, 26-29.

[30] Verpoorte, J. A., Mehta, S., Edsall, J. T. 1967. Esterase activities of human carbonic anhydrases B and C. Journal of Biological Chemistry, 242, 4221-4229.

[31] Lineweaver, H., Burk, D. 1934. The determination of enzyme dissociation constants. Journal of the American Chemical Society, 56, 658-666.

[32] Topal, M. Gülçin, İ. 2014. Rosmarinic acid: a potent carbonic anhydrase isoenzymes inhibitör. Turkish Journal of Chemistry, 38, 894902.

[33] Supuran, C. T. 2016. Structure and function of carbonic anhydrases. Biochemical Journal 473, 2023-2032.

[34] Innocenti, A., Vullo, D., Scozzafava, A. Supuran, C. T. 2008. Carbonic anhydrase inhibitors. Interactions of phenols with the 12 catalytically active mammalian isoforms (CA I-XIV). Bioorganic \& Medicinal Chemistry Letters, 18, 1583-1587. 
[35] Innocenti, A., Vullo, D., Scozzafava, A. Supuran, C. T. 2008. Carbonic anhydrase inhibitors. Inhibition of mammalian isoforms I-XIV with a series of substituted phenols including paracetamol and salicylic acid. Bioorganic \& Medicinal Chemistry, 16, 7424-7428.

[36] Maresca, A., Supuran, C. T. 2010. Coumarins incorporating hydroxy and chloro moieties selectively inhibit the transmembrane, tumorassociated carbonic anhydrase isoforms IX and XII over the cytosolic ones I and II. Bioorganic \& Medicinal Chemistry Letters, 20, 4511-4514.
[37] Carta, F., Temperini, C., Innocenti, A., Scozzafava, A., Kaila, K., Supuran, C. T. 2010. Polyamines inhibit carbonic anydrases by anchoring to zinccoordinated water molecule. Journal of Medicinal Chemistry, 53, 5511-5522.

[38] Gocer, H., Topal, F., Topal, M., Küçük, M., Teke, D., Gülçin, İ., Alwasel, S. H., Supuran, C. T. 2016. Acetylcholinesterase and carbonic anhydrase isoenzymes I and II inhibition profiles of taxifolin. Journal of Enzyme Inhibition and Medicinal Chemistry, 31(3), 441-447. 